\title{
Children of Organized Crime Offenders: Like Father, Like Child? An Explorative and Qualitative Study Into Mechanisms of Intergenerational (Dis)Continuity in Organized Crime Families
}

\author{
Meintje van Dijk ${ }^{1} \cdot$ Edward Kleemans $^{1}{ }^{*}$ \\ Veroni Eichelsheim ${ }^{2}$
}

Published online: 14 April 2018

(C) The Author(s) 2018

\begin{abstract}
This qualitative descriptive study aims to explore (1) the extent of intergenerational continuity of crime in families of organized crime offenders, (2) the mechanisms underlying this phenomenon and (3) the mechanisms underlying intergenerational discontinuity. The study comprised a descriptive analysis of the available numeric information on 25 organized crime offenders based in Amsterdam and their 48 children of at least 19 years of age and a more qualitative in-depth analysis of police files, justice department files and child protection service files of all the family members of 14 of the 25 families. Additionally, interviews with employees of the involved organizations were conducted. In terms of prevalence in official record crime statistics, the results show that a large majority of the organized crime offenders' sons seem to follow in their fathers' footsteps. This is not the case for daughters, as half of them have a criminal record, but primarily for only one minor crime. Intergenerational transmission seems to be facilitated by mediating risk factors, inadequate parenting skills of the mother, the "famous" or violent reputation of the father, and deviant social learning. If we want to break the intergenerational chain of crime and violence, the results seem to suggest that an accumulation of protective factors seem to be effective, particularly for girls. For girls, supervision from a child protection service also seems to work quite well. For boys, we might need a different approach to prevent them from offending.
\end{abstract}

Keywords Organized crime - Intergenerational continuity · Intergenerational discontinuity · Interventions $\cdot$ Parenting $\cdot$ Family

Meintje van Dijk

a.m.m.van.dijk@vu.nl

1 Faculty of Law, Department of Criminal Law and Criminology, VU University Amsterdam, Amsterdam, the Netherlands

2 Netherlands Institute for the Study of Crime and Law Enforcement (NSCR), Amsterdam, the Netherlands 
It is Sunday morning after midnight, 26th of April 2015. The police arrive in Osdorp (Amsterdam, the Netherlands) at the crime scene of a shooting. The victim is a 26-year-old man. His body is riddled with bullets. According to different sources, this young man followed his criminal father's footsteps into the world of organized crime. ${ }^{1}$

The 26-year-old man and his father seem to be a tragic example of the well-known sayings "the apple does not fall far from the tree" and "like father like son". Research shows that this young man is not the only son of a criminal following in his father's footsteps. Many studies show a substantial correlation between the criminal activity of parents and their children (e.g. Besemer et al. 2017; Besemer et al. 2011; Besjes and Van Gaalen 2008; Farrington 2005; Van de Rakt et al. 2006; Thornberry et al. 2003; Van de Weijer 2014; Moors and Spapens 2017). For example, the Dutch Criminal Career and Life-Course Study (CCLS) shows that $30 \%$ of children over the age of 12 with parents who have had more than 15 convictions have a criminal record themselves, as compared to $6.6 \%$ of children with non-convicted parents (van de Rakt et al. 2006). Unfortunately, current theoretical knowledge on intergenerational (dis)continuity and its underlying mechanisms is primarily based on "general" or "petty" offenders. In previous studies, organized crime offenders and their children are typically not included as they are either unlikely to participate or they drop out at an early stage. However, there are reasons to assume that traditional mechanisms underlying intergenerational continuity, such as growing up in poverty, are not directly applicable to children of this serious and potentially very violent group of offenders. On the other hand, it is possible that other traditional mechanisms such as arrest bias or selffulfilling prophecy do apply, but work differently for children of organized crime offenders because the names of their fathers are often in the press, labeled as "serious crime offenders". In short, it is necessary to adjust and improve theoretical models regarding intergenerational continuity by studying this specific group of children. Knowledge about these children is also necessary to develop effective interventions to counteract the risks these children face. The current study is one of the first empirical studies focusing on mechanisms that underlie intergenerational (dis)continuity of organized crime by means of an in-depth qualitative description. The study focuses on mechanisms underlying continuity as well as discontinuity. First, we outline the theoretical background and review what is known about intergenerational continuity of crime and its underlying mechanisms. Next, we present the research questions and method of our study, the results, and a discussion.

\section{How Does Organized Crime Differ from Other Forms of Offending?}

This study focuses on intergenerational (dis)continuity in organized crime. Because the definition of organized crime is a contested issue (e.g. Paoli and Vander Beken 2014), we use the broad description of the Organized Crime Convention, also known as the Palermo Protocol (United Nations Office on Drugs and Crime 2015). This protocol states that organized crime comprises criminal groups engaging in drug trafficking, human smuggling, human trafficking, firearms trading, trafficking stolen vehicles, organized fraud, and money laundering. According to the Convention, the true defining characteristics of organized crime groups are their profit-driven nature and the seriousness of the offenses they commit.

Theoretically, there are several ways in which organized crime differs from other types of crime (Kleemans and De Poot 2008). First, social relations are of great importance as they

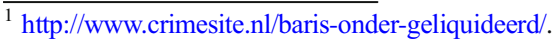


provide access to suppliers, co-offenders, and profitable criminal opportunities. Second, the greater complexity of the criminal activities. Most ordinary crimes require little in the way of effort, planning, preparation, and coordination. Organized crime typically is a long-term process, which often requires months of preparation time and multiple activities are scattered temporally as well as geographically, making coordination necessary. Third, the transnational character of many organized crime activities is unique. This feature makes finding suitable cooffenders and cooperation even more complex, and logistic procedures even more difficult (see, for a review, Kleemans and Van Koppen 2014). The final aspect that is contested concerns the use of violence. Despite some authors deny the necessity of violence as a part of the definition of organized crime and state that the use of violence is overstated, many authors view the use of violence as a critical aspect of organized crime (e.g. Fijnaut et al. 1998; Finckenauer 2005; Von Lampe 2015). Empirically, it is also hard to deny the prevalence of threats and the actual use of violence in organized crime cases (Kruisbergen et al. 2012). Therefore, the use of violence or the willingness to use violence is an important factor in organized crime.

\section{Previous Research on Intergenerational Continuity of Crime}

Intergenerational transmission or continuity refers to the association between the behavior of the parent and that of his or her children (Liefbroer 2005). There is a paucity of research on the intergenerational transmission of organized crime. All well-known datasets, ${ }^{2}$ with data across multiple generations, that have been used to study the prevalence of intergenerational continuity of criminal behavior are based on "petty crime" or "general" offenders and do not include organized crime offenders and their children. This specific group of serious criminals and their children are hard to investigate, as they often stay out of sight of researchers and practitioners. The few existing studies on organized crime offenders and their children are (auto)biographical stories (reviewed by Morselli 2009) and case descriptions of Mafia families (see, for example Follain 2009; Sergi 2017). The research of Anna Sergi is based on 18 proceedings from the Youth Tribunal and the Antimafia District Directorate in Calabria, Italy. Her findings underline the importance of family, blood bonds and Mafia values (such as the code of silence to protect family members) in the transmission of Mafia behavior across generations. Sergi states that these children acquire Mafia behaviors and values and justify their actions through family endorsements. In Calabrian Mafia families, influence and trust are established and preserved through family bonds; family surnames are already an indication of the family status among other families. Both sons and daughters, therefore, play a role in preserving the family's surname and its influence. However, sons seem more willing to behave according to this role than daughters, as they always seem to respect the stereotyped masculine behavior expected of them in Mafia environments, while daughters are either eager to escape their destiny or are victimized (Sergi 2017). After the currently discussed research project was finished, Moors and Spapens (2017) also conducted a case study in the Netherlands: they studied seven Dutch criminal families, with at least one organized crime offender in one of

\footnotetext{
${ }^{2}$ Cambridge Study in Delinquent Development (CSDD), Pittsburgh Youth Study (PYS), Rochester Youth Development Study (RYDS), Ohio Life-Course Study (OLCS), Criminal Career and Life-Course Study (CCLS), and the Transfive study
} 
the four generations. Although they did not specifically focus on intergenerational continuity, as they based their selection on the criminal behavior of the family in general and not on the criminal behavior of the oldest generation, they found the reputation of these families and their deviant values to be of main importance in explaining the participation in crime over generations. Also, some research has been done on the life course of serious criminals. The findings of this research show that these persistent criminals often have a criminal parent themselves (van Koppen et al. 2017). All previous research, however, fails to address the mechanisms through which organized crime is continued across generations. Our research is in that way a unique first step in exploring the processes in these families.

What do existing datasets show us regarding the extent of intergenerational continuity of crime? A recent meta-analysis of Besemer et al. (2017) on 23 datasets or samples in 25 publications of intergenerational transmission of criminal behavior shows that, on average, children with criminal parents are at significantly higher risk for engaging in criminal behavior compared with children without criminal parents (pooled $O R=2.4$ ). Violent crimes are assumed to have the highest rate of intergenerational continuity (Van de Weijer 2014). Transmission is strongest from mothers to daughters, followed by mothers to sons, fathers to daughters, and fathers to sons. However, the chances of intergenerational continuity appear to be higher for sons than for daughters. For example, in the CCLS study (van de Rakt et al. 2006), 57.1\% of the boys with a father who had more than 15 convictions have a criminal record themselves, as compared to $21.5 \%$ of the girls. Furthermore, only $12.8 \%$ of the girls committed more than one crime. Offspring gender is an important factor, as boys and girls tend to react differently to stressful life events such as parental criminal behavior. In general, boys exhibit more externalizing problems, such as delinquency, whereas girls display more internalizing problems, such as anxiety and depression (Capaldi et al. 2002). Important to mention is that, on average, boys are more likely to have a criminal record than girls, regardless of the criminal behavior of their parent. For example, $10.1 \%$ of the boys in the CCLS study with a non-convicted father have a criminal record, compared to $2.8 \%$ of the girls (van de Rakt et al. 2006).

An important question is why children of parents who engage in criminal behavior are more likely to commit crimes themselves, compared to children whose parents do not engage in such behavior. Several theories may be suitable to explain patterns of intergenerational transmission. The most well-known mechanisms underlying intergenerational continuity are the six (not mutually exclusive) mechanisms identified by Farrington (2002), based on research on data of the Cambridge Study in Delinquent Development. The first mechanism is the transmission of risk factors in a so-called cycle of deprivation. According to this explanation, delinquent behavior is not directly transmitted from generation to generation. Instead, continuity is the result of the transmission of risk factors for delinquent behavior, such as poverty and drug abuse. The second mechanism is the mediation of risk factors for delinquent behavior. According to this explanation, whether or not intergenerational continuity occurs depends on the presence of risk factors for criminal behavior. Risk factors exist on three different levels: the individual level (e.g. self-control and intelligence), the family level (e.g. separation of parents and youth traumas), and the meso-level (e.g. school, hobbies, and friends). Third, processes of assortative mating may underlie intergenerational continuity. Assortative mating refers to the finding that men with a criminal record tend to marry women who also have a criminal record. According to Farrington (2002), it is likely that these women apply an inadequate parenting style, marked by neglect, authoritarian discipline, and lack of 
supervision. This parenting style increases the chance that the child gets off track. Various studies confirm the mechanism of assortative mating (e.g. Besjes and Van Gaalen 2008; Bronte-Tinkew et al. 2006; Hoeve et al. 2009; Junger et al. 2013; Nijhof et al. 2007). The fourth mechanism, social learning, is related to Sutherland and Cressey's (1947) differential association theory. According to this theory, younger generations can imitate criminal behavior from their (grand)parents. Sutherland emphasizes that criminal behavior is not simply imitated, but is learned through interactions with other people, such as parents. Children then develop similar attitudes to those of their parents and they will commit delinquent acts if they have learned more motivations to break, rather than to conform to the law (Sutherland and Cressey 1947). This also relates to subcultural theories (Cohen 1955; Miller 1958), which state that crime is the result of individuals conforming to the deviant values and norms of a particular subculture. In this kind of subculture, the individual usually gains respect by committing crimes. The fifth mechanism suggests that intergenerational continuity in convictions can be mediated by genetic factors (Farrington 2002). According to this explanation, criminals have a genetic predisposition for delinquent behavior (e.g. an aggressive personality), which can be transferred to their offspring. However, recent research shows that genes do not seem to play a deterministic role in the explanation of aggressive behavior (Van de Weijer 2014; Widon and Wilson 2015). The sixth and last explanation described by Farrington (2002) suggests that official bias may be responsible for intergenerational continuity. According to this explanation, strong monitoring of criminal families by the police increases the chance of conviction for children growing up in these households (Farrington 2002). Support for this idea has been found in many studies. For example, Van de Rakt and colleagues (2009), used labeling theory to explore a potential selffulfilling prophecy effect. Labeling theory suggests that criminal justice interventions amplify offending behavior. Regarding intergenerational continuity, being labeled as a "child of a criminal" could possibly amplify the criminal behavior of the child. Finally, regarding children of organized crime offenders, the social opportunity structure they grow up in may also explain the intergenerational continuity. It is likely these children benefit from the criminal networks of their criminal parent (Kleemans and De Poot 2008).

However, not all children follow in their criminal parents' footsteps, and various explanations have been put forward to explain such intergenerational discontinuity (e.g. Thornberry 2016). A well-known mechanism potentially underlying intergenerational discontinuity is to be attached to prosocial individuals or organizations (Laub and Sampson 2003). If an individual does not want to put these prosocial attachments at risk, these attachments can help prevent him or her from offending. Particularly the "full family package" (i.e. having a partner and child) seems to protect individuals against delinquent behavior (Van der Geest et al. 2014). Having a job also seems to have a protective effect, depending on the quality and stability of the job (Van der Geest 2011; Laub and Sampson 2003). Besides the potential protective effect of having prosocial attachments, there are also various other types of factors that decrease the risk of offending. Protective factors exist on the same levels as risk factors: individual level (e.g. high IQ), family level (e.g. adequate parenting style and supervision), and mesolevel (e.g. prosocial hobbies and having non-delinquent friends). Support or guidance from a child protection service employee or a therapist can also function as a buffer against delinquent behavior for youth at risk (Tolan et al. 2013). Research shows that exposure to an accumulation of protective factors, seems to have the best protective effect for children (e.g. van de Rakt et al. 2009; Lösel and Farrington 2012). 
There has been some debate on the term "protective factor". According to Farrington et al. (2016), this term has been used inconsistently in the literature. Some researchers have defined a protective factor as a variable predicting a low probability of offending (as the "mirror image" of a risk factor), while other researchers have defined a protective factor as a variable interacting with a risk factor to nullify its effect. However, in general the assumption is that a protective factor decreases the risk of offending.

\section{Current Study}

This study aims to explore (1) the extent of intergenerational continuity of crime in families of organized crime offenders, (2) the mechanisms underlying this phenomenon, and (3) the mechanisms underlying intergenerational discontinuity. We aim to address the following two research questions:

1. To what extent do sons and daughters of organized crime offenders seem to follow in their fathers' footsteps?

2. What are the mechanisms underlying intergenerational continuity and discontinuity of organized crime?

Because the study aims to be explorative and specifically focuses on a selective group of offenders, we do not formulate concrete hypotheses. However, some heuristic assumptions can be derived from the literature. First, the violent aspect of organized crime and the suggestion of previous research that violent crimes have the highest rate of intergenerational continuity (e.g. Bijleveld and Wijkman 2009; Van de Weijer 2014), lead to the assumption that the extent of intergenerational continuity might be higher for children of organized crime offenders than for children of general offenders. Second, more sons than daughters might follow in their fathers' footsteps, because previous findings show that boys are more often involved in criminal activities than girls (e.g. Van de Rakt et al. 2009).

Regarding the mechanisms underlying intergenerational continuity, we question the validity of the cycle of deprivation for explaining the crimes committed by children of organized crime offenders because organized crime relates more to profitable opportunities and wealth than to poverty. On the other hand, mediating risk factors, like youth traumas, may explain intergenerational continuity. This is also true for the mechanism of assortative mating, because research shows that women of organized crime offenders often are also involved in the criminal activities of their partner, such as money laundering or enabling activities (Jonker 2012). Furthermore, we expect patterns of social learning to underlie the transmission. We also expect the self-fulfilling prophecy to play a role in explaining why intergenerational continuity occurs specifically among children of organized crime offenders, such as in cases involving negative publicity regarding the father. Finally, we also expect the social opportunity structure in the child's environment to be a possible explaining factor.

With regard to the mechanisms underlying discontinuity of criminal behavior, possible buffers/protective factors to nullify the risk at intergenerational continuity may include the involvement of child protection services or other family interventions, attachment to prosocial individuals, having an education or a job, and, particularly, the presence of an accumulation of protective factors. 


\section{Method}

\section{Sample}

In this explorative study, we selected organized crime offenders based in Amsterdam (labeled in Dutch as "ABC"; a Dutch acronym for Amsterdam-based Professional Criminal) with one or more children between 19 and 33 years old. Literature shows that most offenders are convicted for the first time before age 19 (Blokland 2006). Furthermore, we wanted the selected families to have at least one child under age 33 because we used files from Child Protection Service Amsterdam (Dutch acronym: JBRA) with information on trauma, hobbies, school, relationships, etcetera, to explore the mechanisms. This child protection organization stores files for a maximum of fifteen years, which means that files of former clients older than 33 years of age are no longer available because child protection usually ends when a child turns 18 years old $(18+15=33)$. We also included the selection criterion that the organized crime offender and his children lived in or nearby Amsterdam.

A total of 25 organized crime offenders (ABCs), all male, met the selection criteria. These 25 ABCs had 44 children ( 25 daughters and 19 sons) between 19 and 33 years old and four sons older than 33 years of age. Our explorative study comprised a descriptive analysis of the available numeric information and a more qualitative in-depth analysis of file information. In the descriptive analysis relating to the extent of intergenerational continuity, no information from child protection services was needed. Therefore, all 25 organized crime offenders and their families, including the four children above the age of 33, were taken into account. This last group is not included in the descriptive analysis regarding the mechanisms because of the lack of information required to study potential mechanisms.

For the in-depth qualitative part, 14 of the 25 families (cases) were selected and analyzed intensively. We chose to support the descriptive analysis of the available numeric information with case studies because underlying mechanisms become particularly clear when studied very intensively (Kruisbergen et al. 2012). In the descriptive analysis, we broadly explored how criminal and non-criminal children score on various aspects. The case studies (based on case descriptions and timelines) were used to unravel the processes in these families and possibilities for intervention. By (re)constructing timelines of family's lives, we were able to explore more in depth which events or factors seemed to be related to patterns of intergenerational (dis)continuity. As the available child protection files contained rich data on the children, we decided to incorporate all seven families of which at least one child had a child protection file in the in-depth study. To counteract bias, we also incorporated seven families with similar characteristics (e.g. family size, age of the children, delinquency of children and mother) of which no child had a child protection file. Given the extensive time needed for the indepth analysis, we decided to make a selection of approximately half (14) of the 25 families. The 14 selected families/cases contain 27 children (of which 12 with a child protection file). Nine of the selected children (33\%) have not been convicted for a serious crime (eight girls and one boy) and the other $18(67 \%)$ have one or more convictions (six girls and 12 boys). This way, we think we were able to explore the mechanisms underlying continuity and discontinuity of crime.

The sample of children of ABCs should not be understood as a representative sample because all samples are, in some way, selective and influenced by police priorities (as well as the failures of criminal groups to escape police attention and shield their activities effectively). 
Because of the relatively small sample size of the current study, descriptive information provided should be carefully interpreted, but quantifying information is not completely redundant. However, qualitative information is most relevant in this pilot study, which has no ambition to be representative for all organized crime offenders in the Netherlands. An important goal of the study is to give a qualitative description of organized crime offenders and their children and check whether certain mechanisms (or different mechanisms) seem to apply to this group. All conclusions are only valid within the context of the sample of the current pilot study. In future research, we want to examine the extent to which certain conclusions are applicable to a broader sample.

\section{Data}

To answer the research questions, we analyzed police files and judicial data of all the family members (father, mother and children) and child protection files of the children, conducted a media search on the fathers, and conducted three additional interviews with employees of the involved organizations in order to gain more information about the mechanisms underlying (dis)continuity of organized crime.

\section{Measures}

The study consisted of a descriptive analysis of the available numeric information, capturing all 25 families, and an in-depth qualitative analysis in which file data of 14 families were studied intensively, by constructing timelines and making extensive case descriptions.

To study the extent of intergenerational continuity for the 25 organized crime offenders and their children, we used the four dimensions of criminal careers (Piquero et al. 2003): (1) participation in criminal activities, (2) frequency and (3) seriousness of the committed crimes and (4) length of the criminal career. We searched the police and judicial files on the factors presented in Table 1. For example, to study the criminal career dimension "seriousness of the committed crimes", we checked (1) the types of crimes fathers and children are registered for (e.g. violent, drugs, traffic), (2) the prevalence of children with an offense related label in the police system (e.g. ABC), and (3) the types of sanctions fathers and children received (e.g. prison sentence, fine, community service). Besides the four dimensions of criminal careers, we additionally checked how many of the children are suspected of committing crime(s) in a group, just like their fathers ${ }^{3}$.

In addition to the extent of intergenerational continuity, the descriptive part also aimed to make an inventory of the possible mechanisms underlying continuity and discontinuity. Therefore, we compared the "criminal" and "non-criminal" children ${ }^{4}$ on the risk and protective factors presented in the coding scheme in Table 2.

For the operationalization of the mechanisms, we were dependent on the factors available in the data. We systematically searched the police and child protection files to score the particular factors in the lives of "criminal" and "non-criminal" children. This numerical description was the starting point for the case studies.

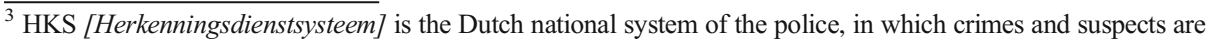
registered (Politie 2015).

${ }^{4}$ A child is considered "criminal" if he or she has at least one conviction for a serious crime (i.e. with pretrial detention).
} 
Table 1 Coding scheme intergenerational continuity

Criminal career dimension Factor(s)

Participation

Frequency

Seriousness

Length criminal career
Number of fathers registered as a suspect in the HKS-Police system (100\%)

Number of children registered as a suspect in the HKS-Police system

Number of crimes fathers are registered for

Number of crimes children are registered for

Types of crimes fathers are registered for (property, drug, violent, weapon, traffic, sexual, other)

Types of crime children are registered for (property, drug, violent, weapon, traffic, sexual, other)

Prevalence of children with a label in the police system (e.g. ABC, AC, Top600)

Types of sanctions fathers received (e.g. prison sentence, fine, community service, see Table 4)

Types of sanctions children received (e.g. prison sentence, fine, community service, see Table 4)

Age at first HKS-registration fathers

Age at first HKS-registration children

Age at most recent HKS-registration fathers

Age at most recent HKS-registration children

Difference between age at most recent and fist HKS registration fathers

Difference between age at most recent and fist HKS registration children

Additional

\section{Data analysis}

In the descriptive part of the study, we analyzed the information retrieved from all 25 families (mostly derived from the police system and the media search) using SPSS. In the in-depth part of the study, we developed case descriptions and timelines in Analyst Notebook, using one for each of the 14 selected families (father, mother, and children). In the timelines, we incorporated important life events and other relevant factors. We studied the cases from the viewpoint of existing theories, and made an estimation of the underlying mechanisms based on the data. The additional interviews were conducted after we had constructed the timelines. All results were anonymized to protect the privacy of the selected families.

\section{Results}

\section{Prevalence}

Of the 25 organized crime offenders, $80 \%$ had at least one child registered as a suspect in the police system. However, the results differ significantly between sons and daughters $[\operatorname{Phi}(1, N=48)=-.432, p<.05]$. Approximately $48 \%$ of the 25 daughters were registered as a suspect in the police data, albeit most of them for only one minor crime, such as petty theft or a traffic violation (see Table 3). Furthermore, only two daughters (12\%) were suspects of three or more crimes and only one daughter spent time in prison (see Table 4).

Compared with daughters, the data in relation to sons of organized crime offenders yield different findings. Approximately $91 \%$ of the 23 sons were known suspects according to the police data. Additionally, the majority of the sons (52\%) committed more than 
Table 2 Coding scheme mechanisms

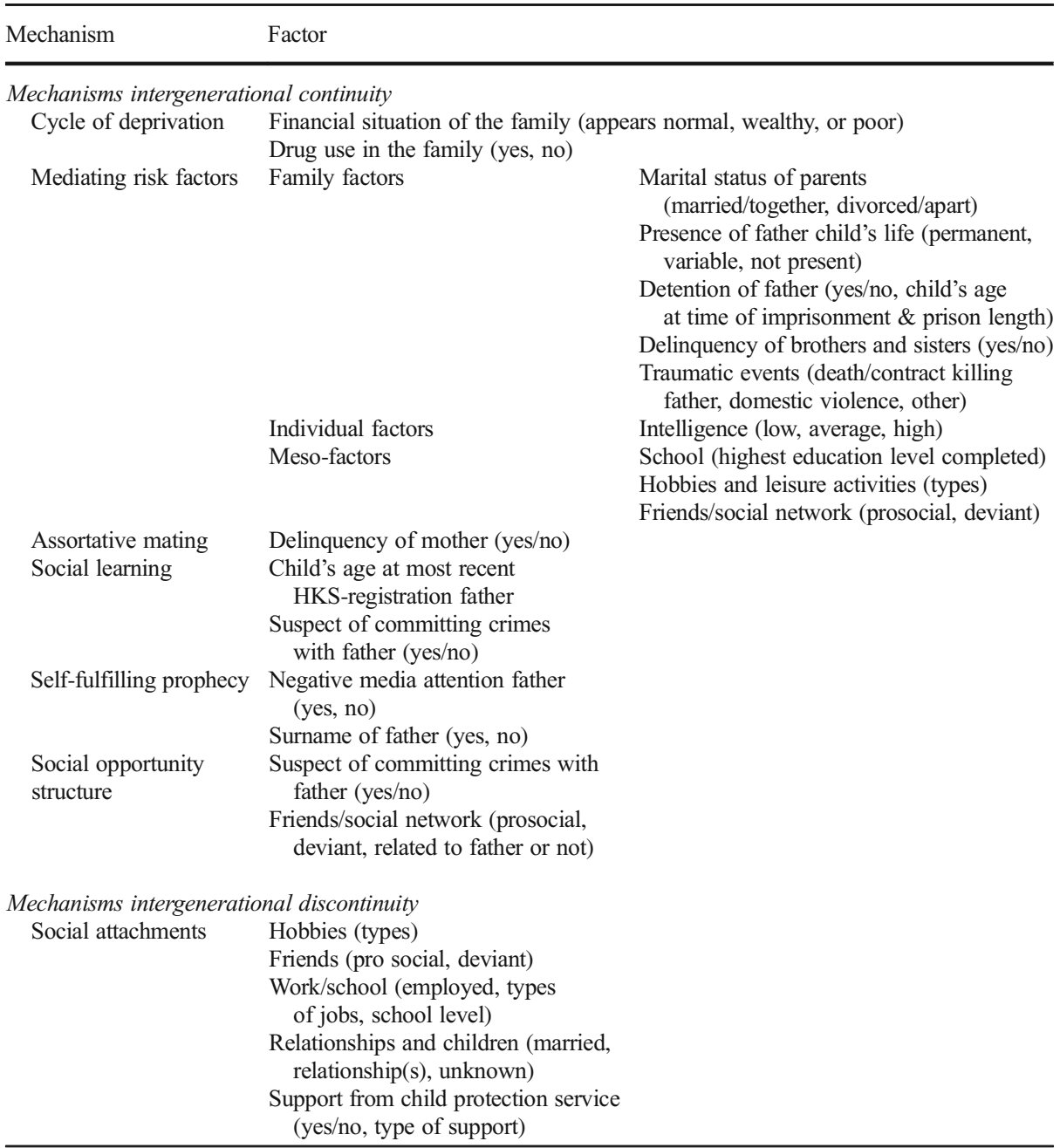

Table 3 Types of offenses for which children are registered

\begin{tabular}{llc}
\hline Type of offense & Daughters $>18$ years $(N=25)$ & Sons $>18$ years $(N=23)$ \\
\hline Property & $5(20 \%)$ & $13(57 \%)$ \\
Violent & $3(12 \%)$ & $17(74 \%)$ \\
Drug & $1(4 \%)$ & $5(22 \%)$ \\
Weapon & $1(4 \%)$ & $14(61 \%)$ \\
Sexual & $0(0 \%)$ & $0(0 \%)$ \\
Traffic & $5(20 \%)$ & $12(52 \%)$ \\
Other & $2(8 \%)$ & $7(30 \%)$ \\
\hline
\end{tabular}


Table 4 Types of sanctions the children received

\begin{tabular}{llc}
\hline Sanction & $\begin{array}{l}\text { Daughters }>18 \text { years } \\
(\mathrm{N}=25)\end{array}$ & $\begin{array}{l}\text { Sons }>18 \text { years } \\
(\mathrm{N}=23)\end{array}$ \\
\hline Prison sentence & $1(4 \%)$ & $10(43 \%)$ \\
Fine & $4(16 \%)$ & $14(61 \%)$ \\
Community service & $0(0 \%)$ & $14(61 \%)$ \\
Training order & $0(0 \%)$ & $1(4 \%)$ \\
Appropriation & $0(0 \%)$ & $3(13 \%)$ \\
Denial right to drive & $0(0 \%)$ & $6(26 \%)$ \\
Civil proceeding & $0(0 \%)$ & $6(26 \%)$ \\
HMS (Measure of Help and Support) & $0(0 \%)$ & $2(9 \%)$ \\
HALT (Alternative Measure for Youth) & $0(0 \%)$ & $2(9 \%)$ \\
Transaction & $1(4 \%)$ & $10(43 \%)$ \\
Discharge from all prosecution & $5(20 \%)$ & $7(30 \%)$ \\
Acquittal/declared not guilty & $1(4 \%)$ & $6(26 \%)$ \\
Dismissal of the case & $0(0 \%)$ & $1(4 \%)$ \\
\hline
\end{tabular}

four crimes and almost half of the sons (43\%) already spent one or more times in prison. Compared to their fathers, the sons have a relatively early age of onset of offending (sons: 16 years, fathers: 23.5 years). Furthermore, police registrations show that in some cases a son of an organized crime offender is involved in a crime together with a son of another offender. It is also known that four sons were involved in a crime together with their father (violent crime, drug offense, and contract killing). Looking at the relative early age of onset of offending, and the number and types of crimes (see Table 3) committed by them, it is likely that the majority of the sons will follow in their fathers' footsteps. Four of the 23 sons already have the same police-label as their father: ABC (Amsterdam-based Professional Criminal).

\section{Mechanisms: Intergenerational Continuity}

Regarding the transmission of risk factors for delinquent behavior, the results show little to no sign of deprivation in organized crime families. Most children of organized crime offenders do not grow up in poverty and, therefore, poverty cannot be a trigger for these children to commit crimes. The in-depth analysis shows that some children even seem to be financially privileged, with some cases appearing to result in antisocial behavior. For example, in the child protection service file of one son, it is stated that his delinquent behavior is probably partly the result of being "spoiled" by his parents. In another file, it is stated that a daughter receives many expensive presents (with a value of more than thousands of euros) and cash from her father, after he has been released from prison. The file states that the daughter started to behave in a "spoiled" manner and became difficult to manage behaviorally at school and at her grandmother's house. We know now that this specific daughter committed two crimes at a later age. Although deprivation in terms of poverty or socioeconomic standards does not seem to be applicable to these types of families, we consider other types of deprivation (e.g., social, moral) that may underlie intergenerational continuation of criminal behavior. For example, strain theory (Merton 1938) states that not only socioeconomical factors can be considered as risk factors to criminal behavior, but that there are also other factors (i.e. "strains"), such as family disruptions, that may have a positive association with delinquent behavior (e.g. Baron 2004). 
Drug use appears to be a common habit in these families. According to the files, at least $44 \%$ of the fathers, $19 \%$ of the mothers, and $16 \%$ of the children had used or continue to use hard drugs. The in-depth analysis shows that children appear to inherit their drug use from their parents. For example, one interviewee states that often both father and mother use drugs and that their children often begin using soft drugs at age 14 or 15 . According to the files and the interviewees, the mothers who use drugs often have a traumatic past, such as being a victim of abuse. Additionally, two of the mothers were recorded to have attempted suicide twice. Whether or not drug use is a mechanism behind the children's involvement in criminal activities is unknown.

Mediation by risk factors could serve as an explaining mechanism. In relation to family factors, children of organized crime offenders seem to face more severe traumatic youth experiences than children of general offenders. For example, these children have a greater risk $^{5}$ of experiencing the death of their father at a relatively young age: $36 \%$ of the 44 children between 19 and 33 years old experienced the contract killing of their father (see Table 5). A remarkable finding is that for the children who were of minor age when the contract killing of their father occurred, no child protection referral ${ }^{6}$ had been generated. Other traumatic events some children have to deal with, are being witness of a police raid, domestic violence, a shooting, or having a suicidal mother.

Of the 12 criminal children for whom their leisure activities were known, muscle training (6) and kick boxing (5) were the most popular hobbies. Some sons train four times a week suggesting that they consider looks and image to be very important. As far as we could test, no individual risk factor has a significant correlation with the criminality of the children. However, the in-depth analysis shows that exposure to different risk factors does seem to have a big impact on the children (see Box 1 for an example).

\section{Box 1 Case description $\mathrm{Z}$}

The father of $\mathrm{Z}$ was killed when $\mathrm{Z}$ was of minor age. Two weeks after the contract killing of his father, $\mathrm{Z}$ is
interrogated for a robbery. During the interrogation, $\mathrm{Z}$ mentions he took the last 2 weeks off because his father
died. Regarding the robbery, $\mathrm{Z}$ states he does not know why he did it (together with another boy), and he
mentions he was not himself. A couple of months later, $\mathrm{Z}$ is convicted with 8 months juvenile detention as
sanction. After juvenile detention, $\mathrm{Z}$ keeps making mistakes. When $\mathrm{Z}$ is 23 years of age, he mentions the
contract killing of his father during an interrogation: "I just do not know what to do with my life. Boys look up
to me. My dad has been shot in (date withheld) and because of that story boys look up to me and I have to
admit that the death of my father sure is something." When $\mathrm{Z}$ is 25 years old, he mentions the contract killing
of his father again when a police officer asks him what happened with his life: "One person has more luck in
his life than the other. My father died in [date withheld]. Before that, my parents were divorced. The last 9
months before he died, I lived with my father. My father has been shot. I was 14 years old when that happened.
My mother did not want me anymore, so I moved to my grandma's". When his grandfather got ill, Z also had to
leave this house, and after that he stayed at various addresses, including those for homeless youth. Z is not
accepted at any school, because he would be too traumatized to learn.

Assortative mating also seems an important mechanism for explaining the intergenerational continuity in organized crime families. First, the descriptive analysis shows that mothers of delinquent children more often have committed crimes themselves (50\%), than mothers of non-delinquent children $(22 \%), \operatorname{Phi}(1, N=44)=.82, p=.063$. Second,

\footnotetext{
${ }^{5}$ In the CCLS dataset on general offenders, $10 \%$ of the children (with an average age of 22 years old, compared to 23 in the current sample) is faced with the (un)natural death of their father (van de Rakt et al. 2009).

${ }^{6}$ If an individual (for example, a citizen or the police) has serious concern about a child, he or she can report this in a child protection referral.
} 
Table 5 Father killed

Father not killed

Father killed

Child not criminal $(N=18)$

Child criminal $(N=26)$

$12(67 \%)$

$16(62 \%)$

$28(64 \%)$

$6(33 \%)$

$10(38 \%)$

Total $(N=44)$

$16(36 \%)$

the in-depth analysis shows that criminal mothers do not seem to possess the necessary parenting skills to adequately raise their children. According to various files of Child Protection Service Amsterdam, these mothers are incapable of providing the structure their children need. Various files state that a child's problem behavior is the consequence of a lack of predictability, structure, rules, and safety at home. The interviewees also name the importance of the mother. As one interviewee who coordinates child protection referrals states: "These children don't have their father as a role model, because he is often away/in prison. Therefore, their mother is of crucial importance. If she is also involved in criminal activities, or is calling names at the police or child protection employees when they want to enter, and doesn't allow her children to talk to these people, then it gets really difficult for the children to ever escape this environment." Furthermore, the partner preference of the children also seems based on assortative mating; sons often choose girlfriends who accept their criminal behavior and daughters often choose a criminal partner.

Social learning is another useful explanation for the process of intergenerational continuity. In all 25 investigated families, the fathers were involved in criminal activities after the birth of their children. Moreover, the children often witnessed crimes or violence committed by their father. Four sons even committed a crime together with their father. The in-depth analysis shows that children of organized crime offenders seem to grow up with different norms and values than other children. The socialization that the use of violence is normal to solve problems, even seems to result in violent behavior for sons. For example, one son witnessed his father using violence and threatening someone with a gun. This son committed his first maltreatment at age 13. Various sons also make threats during an arrest, for example: "You and your children will die, you are going to regret this. I will remember your face. G [friend of father] will take care of everything" and: "If I see you again, I will beat you up".

Regarding the self-fulfilling prophecy mechanism, we looked at negative press releases regarding the father. A striking finding, and not in line with our expectations, is that there are relatively more negative press releases on fathers of non-delinquent children (72\%) than on fathers of criminal children (54\%). Moreover, fathers of non-delinquent children are significantly more likely to have their own Wikipedia page $\left(X^{2}(1)=4.85, p<.05\right)$. This implies that media attention is negatively correlated to intergenerational transmission. The fact that there are no press releases on the eight fathers with a non-Dutch ethnicity seems a possible explanation for this result. It is possible that there is a "news effect" in the Dutch media, regarding organized crime offenders, in which ethnicity influences the amount of media attention. The in-depth part of the study shows that in some cases media attention for fathers seem to have an impact on the children. As one father mentioned, "The horrible accusations in the media had a big impact on me and my family". In one case, a mother even changed her daughter's surname after her father was constantly in the news for the crimes he committed. A possible consequence of negative press regarding the father concerns deterrence effects. Some children, especially daughters, do not like to be associated with their criminal father. For these 
daughters, the negative press could have a protective effect, because it stimulates them to follow their own path and not the footsteps of their criminal parent.

The reputation of the father seems to work quite different for sons than for daughters. For these individuals, it appears to result in a social opportunity structure, as sons make use of the reputation of their fathers to commit crimes themselves. Moreover, this reputation seems to attract criminal friends, which also facilitates offending. According to one interviewee, the reputation of these fathers is also one of the reasons that child protection services do not become involved and that some informants (such as school) hesitate to give information. According to this interviewee, police are not "tough" enough and thereby facilitate the organized crime offenders. This interviewee states that "getting away with crimes" is the most important risk factor for the children to follow in their fathers' footsteps. Whether the children make use of the criminal network of their father to commit crimes is not clear. The files do show that some children of organized crime offenders hang out together, which suggests that the possibilities to start a career in organized crime are bigger for these children.

The last mechanism that seems to foster intergenerational continuity is the "closed" family system of these families and the fact that child protection services have difficulty reaching them. Both the police and child protection services do not have a clear understanding of the situation of the children. Furthermore, child protection services seem to be quite hesitant to get involved due to the fathers' reputation for violence. Therefore, it is possible that these children do not receive the necessary support to prevent them from following in their fathers' footsteps.

\section{Mechanisms: Discontinuity}

Looking at the mechanisms underlying discontinuity of criminal behavior, theories stressing the importance of social bonds do not seem to hold for children of organized crime offenders. The current study shows, for example, that the majority of the criminal children have a job and a relationship. Therefore, these social bonds do not seem to be particularly protective. We might, however, question the prosocial character of the relationships (violent/approving criminal behavior). Furthermore, the protective effect of a job depends on the quality and stability of the job (Van der Geest 2011; Laub and Sampson 2003).

A few positive exceptions are some non-criminal daughters who moved out at age 18 , have completed education, currently hold a job, do not seem to have a criminal partner or friends, and have a mother with no registered crimes. It is possible that this accumulation of factors may prevent the continuity of criminal behavior. Moreover, it seems that maternal parenting skills may play a crucial role in preventing the transmission. Support or supervision from a child protection service also seems to have a protective effect for daughters. However, this is not the case for sons, who often act strategically in relation to child protection services, do not want to receive support or supervision (similar to their parents), and in most cases do not stop committing crimes after a period of supervision. Four of the 18 children between 19 and 33 years old who did not commit a serious crime, have a record at Child Protection Service Amsterdam (22\%). For delinquent children, this is $31 \%$ (eight out of 26). The four nondelinquent children known to the child protection service received support, and the eight criminal children received either support (4) or probation (4). Only one mother applied for support from child protection services. It is striking that three of the four sons who are now also an ABC-criminal, and started committing crimes at age 13 or 14, are not known to child protection services. Also, only two sons received support from a child protection service, and the other sons are only known to child protection services because of a probation measure. 


\section{Conclusion and Discussion}

This study aimed to explore the extent of intergenerational continuity of crime in families of organized crime offenders and the mechanisms underlying intergenerational continuity and discontinuity. In terms of prevalence in official record crime statistics, the results show that a large majority of the organized crime offenders' sons seem to follow in their fathers' footsteps. This is not the case for daughters, where while half of them had criminal records, these were primarily only for one minor crime. Regarding their criminal activities, the daughters seem little to no different from daughters of general offenders (Van de Rakt et al. 2006). Of course, it might be possible that the daughters are criminally active, and stay out of sight of the police. However, it is also likely that these daughters are not criminally active, following the existing gender literature, which states girls more often tend to internalize rather than externalize their problems (Capaldi et al. 2002). The findings that two daughters of organized crime offenders had an eating disorder and one attempted suicide support this suggestion, as well as the strain theory.

Intergenerational transmission seems to be facilitated by mediating risk factors, inadequate parenting skills of the mother, the "famous" or violent reputation of the father, and deviant social learning. In contrast to children of general offenders (West and Farrington 1977), some children of organized crime offenders do commit crimes together with their criminal parent. Furthermore, the results suggest a wider impact of violent norms and behavior on intergenerational transmission; both violence committed outside the house and domestic violence are transferred from parents to their children. The violent aspect also appeared in the leisure activities of the children (boxing) and in the socialization of what is normal behavior. The committed crimes of the father also seem to result in a violent reputation of the family, which seems to attract criminal friends and co-offenders for sons and also seems to have an adverse effect on the access of child protection services to these families. Child protection workers, for example, seem hesitant to approach these families and do not apply interventions that are normal in less serious cases. It is possible that in organized crime families, the "closed" family systems and the use of violence and drugs are part of a deviant lifestyle and subculture (Cohen 1955; Miller 1958). This mechanism, which might be coined "the family cycle of multiplying violence and retreating agencies", seems to be present in these families and obviously needs more research attention.

If we want to break the intergenerational chain of crime and violence, the results of this pilot study seem to suggest that an accumulation of protective factors is effective (particularly for girls) to counteract the risk these children face. For girls, supervision from a child protection service also seems to work quite well. For boys, we may need a different approach to prevent them from offending, because child protection services do not appear to reach them. It is possible that the lack of support for sons, despite the traumatic situations they grow up in, contributes to the substantial intergenerational continuity found in this study. Important to note is that appropriate interventions are likely to differ for boys and girls given the gender differences in behavioral problems (externalizing versus internalizing). Finally, the parenting skills of the mothers seem to play a crucial role in the prevention of transmission. It is likely that the important role of the mother is related to the finding that these children face a lot of traumatic events. Having a mother who is capable of providing warmth and stability in the chaotic lives of these children may be crucial to prevent these children from following in their fathers' footsteps. 


\section{Strengths and Limitations}

A limitation of this study is that the results are mainly based on police registrations, in which crimes and suspects are registered. Most other studies on intergenerational continuity are based on convictions and therefore the comparability of the results is limited. However, a judge convicts a suspect in approximately nine out of ten cases (Besjes and Van Gaalen 2008); therefore, we can assume with considerable certainty that a son or daughter with multiple HKS-registrations went off track. Moreover, it is likely that HKSregistrations are a better measure for this group of children, because the study shows this group often "gets away" with committed crimes. A second limitation of the study is its small population. Therefore, the findings are not representative for all children of organized crime offenders in the Netherlands. However, the results are representative for the ABC-criminals in Amsterdam, because all ABC-criminals with children between 19 and 33 years of age were examined in the descriptive part. Additionally, the study gives new insights regarding intergenerational (dis)continuity in organized crime families. A third limitation of the study is the use of file information. The examined files were developed for operational goals and not for scientific research. Moreover, the quality of the information differed between files and some aspects regarding the mechanisms were unavailable. To mitigate this limitation, conducting interviews with members of the population is an option, but unfortunately this was not possible in the current study. However, we did interview two police officers and one employee of a child protection service for additional information. Furthermore, to gain as much information on the family members as possible, we used information from different types of files: police files, judicial files and child protection service files. Another limitation is that most of the information regarding the protective mechanisms is retrieved from child protection files. This can distort the results because children known to child protection services are probably not representative for the population. Regarding the mechanisms underlying intergenerational continuity, we also retrieved information from social interrogations and other sources. However, for children who were not registered as suspects in the police system, we mainly used child protection services files to investigate the protective mechanisms. We tried to gain additional information on the children not known in the police and child protection services system during the interviews. But, unfortunately, the additional information we retrieved regarding the individual cases was limited. Furthermore, we can also question the assumption that a child is not criminal when he or she is unknown in the police system. It is possible that these children are criminally active, but do not get caught. Another aspect of discussion is the focus of the study on children between 19 and 33 years old. It is possible that some children are still at the start of their criminal career and their number of committed crimes is relatively low. However, if we would raise the age limit, the small sample would reduce even further because of the lack of (child protection) information on children of 33 years and older. The best method would be to follow this group in time and compare the results to a group of children of which their parents do not commit crimes or commit "general" crimes. However, these type of respondents and families are not easily accessible with more traditional research tools and methods, and therefore, this type of research is very time consuming. The current study serves as a first in depth exploration into patterns of intergenerational (dis)continuity in a very specific group of offenders: organized crime offenders and their children. The effects on the lives of their children was leading in the approach taken. Finally, we were not able to investigate all possible 
mechanisms, such as genetic factors and official bias, due to lack of information in the types of data available for the study. However, as a first step in this field of research, we underline that the current study did offer a lot of insight regarding the mechanisms.

While there are limitations, there are also substantive strengths in our study that we want to highlight. This study has a specific focus on a group of children who remained under the radar of researchers until now. To our knowledge, this is one of the first in-depth studies that explores the lives of children of a specific group of serious criminals. By combining police, judicial, and child protection files, rich information became available on a specific, but complete population (ABC-criminals with at least one child aged between 19 and 33 years old). Another strength of the current study is its initial selection criterion, which was based on the comparability of the criminality of the fathers and not only on the behavior of the children. The majority of studies, such as the CSDD and the PYS, selected their sample based on the behavior of the child instead of the parent, which can overestimate the extent of intergenerational continuity. Moreover, most studies on intergenerational continuity focus only on father and sons, and the current study also captures the criminality of daughters to gain more insight into gender specific mechanisms. Furthermore, most other studies do not focus on a specific type of crime. Motives, skills, and character traits of offenders can differ between different types of crimes, so there are reasons to assume the mechanisms underlying intergenerational continuity may also differ (van de Weijer 2014). Another strength of the study is its focus on protective mechanisms underlying discontinuity of criminal behavior. There is limited literature on protective mechanisms and previous research is mainly focused on protective factors against delinquency in general and not against transmission. This study aimed to unravel the mechanisms underlying discontinuity, by capturing non-criminal children and examining the factors that may prevent these children from following in their parents' footsteps. The use of case studies is an adequate method to open the black box regarding the mechanisms. Quantitative data alone does not give insight into the underlying processes influencing the behavior of the child. The study also contributes to theory development, because intergenerational (dis)continuity for this group of offenders was not studied before. We examined the data using a top-down approach (from existing theories), but we also used a bottom-up approach to explore other mechanisms than the ones known in the literature. For example, the results suggest a wider impact of violent norms and behavior in the process of intergenerational transmission.

\section{Implications for Practice and Future Research}

Based on the current study we would recommend to focus future studies on: (1) the daughters of organized crime offenders and the protective mechanisms (e.g. by means of interviews with the population); (2) the social network of the sons, to unravel how some of them know each other (e.g. via their fathers); (3) issues such as the news effect and differences based on ethnic backgrounds of families; (4) individual risk factors and mechanisms as official bias and genetic processes; and (5) the wider impact of violence in the intergenerational transmission of organized crime.

To conclude, the current study has provided unique explorative insight into the lives of children of organized crime offenders. Based on our findings, there are reasons to assume that theoretical mechanisms known in the literature may not apply to children of organized crime offenders and that these children should be considered a specific group and should be targeted accordingly in research, practice, and policy. 
Open Access This article is distributed under the terms of the Creative Commons Attribution 4.0 International License (http://creativecommons.org/licenses/by/4.0/), which permits unrestricted use, distribution, and reproduction in any medium, provided you give appropriate credit to the original author(s) and the source, provide a link to the Creative Commons license, and indicate if changes were made.

\section{References}

Baron, S. W. (2004). General strain, street youth and crime: A test of Agnew's revised theory. Criminology, 42, $457-483$.

Besjes, G., \& van Gaalen, R. (2008). Jong geleerd, fout gedaan? Den Haag: Centraal Bureau voor de Statistiek.

Besemer, S., Ahmad, S. I., Hinshaw, S. P., \& Farrington, D. P. (2017). A systematic review and meta-analysis of the intergenerational transmission of criminal behavior. Aggression and Violent Behavior, 37, 161-178.

Besemer, S., van der Geest, V., Murray, J., Bijleveld, C. C. J. H., \& Farrington, D. P. (2011). The relationship between parental imprisonment and offspring in England and the Netherlands. British Journal of Criminology, 51, 413-437.

Bijleveld, C. C. J. H., \& Wijkman, M. (2009). Intergenerational continuity in convictions: A five-generation study. Criminal Behaviour and Mental Health, 19(2), 142-155.

Bronte-Tinkew, J., Moore, K. A., \& Carrano, J. (2006). The father-child relationship, parenting styles and adolescent risk behaviours in intact families. Journal of Family Issues, 27, 850-881.

Capaldi, D. M., DeGarmo, D., Patterson, G. R., \& Forgatch, M. (2002). Contextual risk across the early life span and association with antisocial behavior. In J. B. Reid, G. R. Patterson, \& J. J. Snyder (Eds.), Antisocial behavior in children and adolescents: A developmental analysis and model for intervention (pp. 123-145). Washington, DC: American Psychological Association.

Cohen, A. K. (1955). Delinquent boys: The culture of the gang. Glencoe. IL: Free Press.

Farrington, D. P., Ttofi, M. M., \& Piquero, A. R. (2016). Risk, promotive, and protective factors in youth offending: Results from the Cambridge study in delinquent development. Journal of Criminal Justice, 45, 63-70.

Farrington, D. P. (2005). Integrated developmental and life-course theories of offending: Advances in criminological theory 14. New Brunswick, N.J: Transaction Publishers.

Farrington, D. P. (2002). Developmental criminology and risk-focused prevention. In M. Maguire, R. Morgan, \& R. Reiner (Eds.), The Oxford handbook of criminology (pp. 657-701). Oxford: Oxford University Press.

Fijnaut, C., Bovenkerk, F., Bruinsma, G., \& van Bunt, H. (1998). Organized crime in the Netherlands. Den Haag: Kluwer.

Finckenauer, J. O. (2005). Problems of definition: what is organized crime? Trends in Organized Crime, 8(3), 63-83.

Follain, J. (2009). The last godfathers: Inside the Mafia's most infamous family. New York: St. Martin' s Press.

Geest, V.R. van der, (2011). Working their Way into Adulthood: Delinquency and employment in high risk boys to age 32 [doctoral thesis]. Amsterdam: Vrije Universiteit.

van der Geest, V., Liefbroer, A. C., \& Bijleveld, C. C. J. H. (2014). Criminality and family formation: Effects of marriage and parenthood on criminal behaviour for men and women. Crime \& Delinquency, 60(8), 12091234.

Hoeve, M., Dubas, J. S., Eichelsheim, V. I., van der Laan, P. H., Smeenk, W., \& Gerris, J. R. M. (2009). The relationship between parenting and delinquency: A meta-analysis. Journal of Abnormal Child Psychology, $37,749-775$.

Jonker, S. (2012). Het ABC van beroepscriminelen [Master thesis]. Amsterdam: Vrije Universiteit.

Junger, M., Greene, J., Schipper, R., Hesper, F., \& Estourgie, V. (2013). Parental criminality, family violence and intergenerational transmission of crime within a birth cohort. European Journal of Criminal Policy and Research, 19(20), 117-133.

Kleemans, E. R., \& van Koppen, M. V. (2014). Careers in organized crime. In G. Bruinsma \& D. Weisburd (Eds.), Encyclopedia of criminology and criminal justice (pp. 285-295). New York: Springer.

Kleemans, E. R., \& de Poot, C. J. (2008). Criminal careers in organized crime and social opportunity structure. European Journal of Criminology, 5, 69-98.

van Koppen, M. V., van der Geest, V. R., \& Kleemans, E. R. (2017). Doorgroeiers in de misdaad: De criminele carrières en achtergrondkenmerken van jonge daders van een zwaar delict. Den Haag: Politie \& Wetenschap.

Kruisbergen, E.W., Bunt, H.G. van de, \& Kleemans (2012). Georganiseerde criminaliteit in Nederland. Vierde rapportage op basis van de Monitor Georganiseerde Criminaliteit. Reeks Onderzoek en Beleid 252. Den Haag: WODC / Boom Juridische Uitgevers. 
Lampe, K. von, (2015). Definitions of Organized Crime. Retrieved from: http://www.organized.crime. de/organizedcrimedefinitions.Htm.

Laub, J., \& Sampson, R. (2003). Shared beginnings, divergent lives: Delinquent boys to age 70. Cambridge/ London: Harvard University Press.

Liefbroer, A. C. (2005). Valt de appel nog steeds niet ver van de boom? Over intergenerationele overdracht van demografisch gedrag. Oratie 16 juni 2005. Amsterdam: Vrije Universiteit.

Lösel, F., \& Farrington, D. P. (2012). Direct protective and buffering protective factors in the development of youth violence. American Journal of Preventive Medicine, 43(2), 8-23.

Merton, R. (1938). Social structure and anomie. American Sociological Review., 3(5), 672-682.

Miller, W. (1958). Lower class culture as a generating milieu of gang delinquency. Journal of Social Issues., 14(3), 5-20.

Moors, H., \& Spapens, T. (2017). Criminele families in Noord-Brabant. Een verkenning van generatie-effecten in de georganiseerde misdaad. Den Haag: EMMA.

Morselli, C. (2009). Inside criminal networks. New York: Springer.

Nijhof, K. S., Engels, R. C. M. E., Wientjes, K. A. N., \& de Kemp, R. A. T. (2007). Crimineel gedrag van ouders en kinderen. Pedagogiek, 27, 29-44.

Paoli, L., \& Vander Beken, T. (2014). Organized crime. A contested concept. In L. Paoli (Ed.), The Oxford handbook of organized crime (pp. 13-31). New York: Oxford University Press.

Piquero, A. R., Farrington, D. P., \& Blumstein, A. (2003). The criminal career paradigm. Crime and Justice, 30, $359-506$.

Politie (2015). HKS-applicatie. Retrieved from: http://amlkorpsnet.politie.local/applicaties/applicaties_ info/hks.aspx

van de Rakt, M., Nieuwbeerta, P., \& Apel, R. (2009). The association of criminal convictions between family members: The effects of siblings, fathers and mothers. Criminal Behaviour and Mental Health, 19, 94-108.

van de Rakt, M., Nieuwbeerta, P., \& de Graaf, N. D. (2006). Zo vader, zo zoon? De intergenerationele overdracht van crimineel gedrag. Tijdschrift voor Criminologie, 4(48), 345-360.

Sergi, A. (2017). From mafia to organised crime. A comparative analysis of policing models. London: Palgrave Macmilan.

Sutherland, E. H., \& Cressey, D. R. (1947). Principles of criminology (7th ed.). Philadelphia: J.B. Lippincott Company.

Thornberry, T., Freeman, Gallant, A., Lizotte, A., Krohn, M., \& Smith, C. (2003). Linked lives: The intergenerational transmission of AntiSocial behaviour. Journal of Abnormal Child Psychology, 31(2), 171-184.

Tolan, P. H., Henry, D. B., Schoeny, M. S., Lovegrove, P., \& Nichols, E. (2013). Mentoring programs to affect delinquency and associated outcomes of youth at risk: A comprehensive meta-analytic review. Journal of Experimental Criminology, 10(2), 179-206.

United Nations Office on Drugs and Crime (2015). Organized Crime. Retrieved from: http://www.unodc. org/unodc/ar/organized-crime/index.html.

van de Weijer, S. G. A. (2014). The intergenerational transmission of violent offending [doctoral thesis]. Amsterdam: Vrije Universiteit.

Widon, C. S., \& Wilson, H. W. (2015). Intergenerational transmission of violence. Violence and Mental Health, $2015,27-45$. 